\title{
A PRÉ-ESCOLA OBRIGATÓRIA NO BRASIL E OS DESAFIOS NA FORMAÇÃO DE PROFESSORES
}

Jaqueline Delgado Paschoal ${ }^{*}$

\section{INTRODUÇÃO}

Podemos afirmar que, nas últimas três décadas, houve um avanço significativo da legislação em relação à educação no Brasil, pois a Constituição Federal (1988) reconheceu a educação como direito de todos e dever do Estado, além de garantir igualdade de condições para o acesso e permanência na escola pública, gratuidade e educação de qualidade. Para a garantia desse direito, a Lei de Diretrizes e Bases da Educação Nacional (1996) estabelece a educação infantil como a primeira etapa da Educação Básica, com a finalidade de proporcionar o desenvolvimento integral da criança até cinco anos de idade. Além disso, determina que a avaliação, nessa etapa, não tem a função de promover a criança para o ensino fundamental e nem de retê-la na pré-escola, mas de acompanhar seu desenvolvimento ao longo do processo educativo (BRASIL, 1996).

Apesar dos avanços registrados, constatamos um descompasso nas determinações legais no âmbito dos direitos, visto que "a LDB 9.394/96, ao mesmo tempo em que regulamentou a educação infantil, determinou a municipalização desta etapa e do ensino fundamental" (NASCIMENTO, 2011, p. 152). Por outro lado, o Estado, como federação, não garante a distribuição igualitária de recursos e a manutenção destes nos diferentes níveis de ensino. Na realidade, cabe a ele responder pela garantia dos direitos sociais, ainda que haja distribuição de competências entre os entes federados, para a oferta da educação (NASCIMENTO, 2011).

Quanto ao processo formativo de professores, a LDB (1996) avança quando exclui a participação de professores leigos no sistema de ensino e destaca a obrigatoriedade da formação em nível superior, em cursos de licenciatura e de graduação plena. Entretanto, retrocede do ponto de vista da qualificação quando admite, como formação mínima para o exercício do magistério na educação infantil e nos primeiros anos do ensino fundamental, a modalidade normal (PASCHOAL; BRANDÃO, 2015). Sobre essa questão, Saviani (2009, p. 148) reconhece que a precariedade das políticas gformativas, mesmo com contínuas mudanças, não conseguiu “estabelecer um padrão

\footnotetext{
${ }^{(*)}$ Pós-doutora em Educação pela Universidade Estadual Paulista Julio de Mesquita Filho (UNESP - Campus Assis). Doutora em Educação pela Universidade Estadual de Maringá (UEM). Docente no Programa de Pós-Graduação em Educação - Mestrado e Doutorado da Universidade Estadual de Londrina. E-mail: jaquelinedelgado@uol.com.br.
} 
minimamente consistente de preparação docente, para fazer face aos problemas enfrentados pela educação escolar em nosso país".

Além disso, muitos profissionais atuam sem a formação mínima exigida pela legislação, já que a realidade demonstra que, para as populações pobres em geral, são oferecidas formas de atendimento de baixa qualidade. A falta de conhecimento didático-pedagógico, sobretudo, na creche, reforça a ideia de que, para lidar com a criança pequena, qualquer pessoa serve, seja ela mãe voluntária ou professor leigo e sem formação específica (CAMPOS, 1994).

Para Paschoal e Brandão (2015), o fato de a Emenda Constitucional $n^{\circ}$ 59/2009 ter determinado o ensino obrigatório dos quatro os dezessete anos, até 2016, e ter excluído a creche de tal prescrição fragiliza ainda mais a educação das crianças menores de três anos, pois, conforme Didonet (2009, p. 2), corre-se o risco de dividir a "educação infantil em duas partes: a pré-escola, obrigatória, que passa a um nível de prioridade, ressaltando sua importância educacional; a creche, não obrigatória, que perde importância educacionalmente".

Outra questão apontada por Didonet (2009) diz respeito ao recurso orçamentário, visto que os sistemas de ensino poderão direcionar recursos somente para a pré-escola, deixando a creche em plano secundário, fragmentação esta que se distancia da concepção de educação infantil como direito de todas as crianças até cinco anos de idade, pois não considera a "relevância dos três primeiros anos de vida na formação das estruturas básicas que sustentam a aprendizagem ao longo da vida" (DIDONET, 2009, p. 2),

Nascimento (2011, p. 155) argumenta que, se a obrigatoriedade, por um lado, beneficia as crianças pobres de quatro e cinco anos, visto que estas terão o direito à educação, por outro lado, “a medida fragmenta a educação infantil, pois exclui as crianças de zero a três anos e abala a concepção de creche como espaço legítimo de educação e cuidado da criança pequena". Na realidade, o paradoxo encontra-se na existência de duas medidas legais diferentes para a educação na infância, o que perpetua a divisão histórica desse nível de ensino.

É importante lembrar que, antes da aprovação da EC59/09, a criança que frequentava a préescola era encaminhada, compulsoriamente, para o primeiro ano, em função da extensão do ensino fundamental de oito para nove anos de duração, o que aconteceu por determinação da Lei n. $^{\circ}$ 11.274, de 2006. Essa determinação legal, segundo Campos (2010a, p.10), foi considerada polêmica do ponto de vista pedagógico, "pois foi adotada sem que se previsse um período de transição, nem regras claras sobre a idade exata em que as crianças deveriam ser aceitas no primeiro ano". A arbitrariedade também aconteceu no campo da formação, pois não houve tempo hábil para que "os 
professores se preparassem para os alunos mais novos, nem esclarecimentos aos pais sobre os motivos dessa mudança, nem a adaptação de prédios, equipamentos, mobiliários e materiais escolares" (CAMPOS, 2010a, p. 10).

Por outro lado, Campos (2010a) explica que, em relação ao acesso à escola, a mudança pode ser considerada positiva, ainda que tardia, pois, em 2007, foram apresentados, pelo escritório regional da Unesco, dados que apontavam que, entre 41 países da América Latina e do Caribe, apenas quatro mantinham o ingresso da criança na primeira série aos 7 anos de idade, entre eles, o Brasil, El Salvador, Guatemala e Nicarágua. Campos (2010, p. 11) ressalta, ainda, que "a escola de nove anos deve representar para os alunos melhores oportunidades de acesso ao conhecimento e não a antecipação de experiências de fracasso". Desse modo, para a autora, não basta a ampliação da escolaridade, mas a garantia de condições para que as crianças aprendam.

Silva (2011, p. 375), ao analisar a implantação da obrigatoriedade, considera que a formação de professores se coloca como um grande desafio, pois, "diante do imperativo da ampliação da oferta de vagas, haverá, também, a necessidade premente de mais profissionais qualificados para essa área". Assim, a preocupação não deve ser somente o aumento do número de profissionais, mas a definição do perfil de profissional para atuar com crianças de quatro e cinco anos de idade.

Nesse sentido, o objetivo desta pesquisa de caráter bibliográfico é discutir: os avanços e os retrocessos da prescrição legal que determina a obrigatoriedade da pré-escola no Brasil, e os inúmeros desafios e perspectivas em relação à formação inicial e continuada de professores da educação infantil. A defesa é pela consolidação de um trabalho pedagógico que proporcione o desenvolvimento das muitas linguagens das crianças até os cinco anos de idade.

\section{DESENVOLVIMENTO}

Do ponto de vista da ação docente, acreditamos que a falta de entendimento da EC59/09 pode levar a um retrocesso histórico em relação aos serviços prestados na educação infantil, já que “a pré-escola pode ser compreendida como antecipação da escola, como ocorreu nos anos de 1970 e 1980, por ocasião da formalização da educação pré-escolar no Brasil” (NASCIMENTO, 2011, p. 155). Tal fato ocorreu, segundo Pinazza e Santos (2016, p. 32), porque, "no final da década de 1970, admitiu-se a existência de desigualdades sociais e econômicas no país e acreditou-se que a educação seria uma das chaves para um suposto desenvolvimento".

Nesse contexto, os programas elaborados pelo setor público, em meados das décadas de setenta e oitenta, adotaram a educação compensatória como função principal da pré-escola e a 
abordagem da privação cultural como referência na organização do trabalho dos professores. Essa teoria defendia que a pré-escola seria capaz de suprir a carência afetiva e nutricional das crianças de baixa renda e de minimizar os altos índices de repetência nas primeiras séries do ensino regular (PINAZZA; SANTOS, 2016).

A lógica de superação das deficiências de uma escola, que se revela incapaz de promover índices mais exitosos, sem olhar para o seu interior e atribuindo à educação infantil o papel compensatório e preparatório, revelou-se falaciosa, a começar pela tese que a sustentava: a de privação cultural (p. 34).

Para Kramer (1995, p. 96), os documentos oficiais da época concebiam as crianças como "culturalmente carentes e atribuíam ao atendimento pré-escolar a solução para suas defasagens escolares". Nesse sentido, a privação cultural também se relacionava à privação linguística, assim, culpabilizava-se a própria criança "pelo seu fracasso, não sendo questionada a escola, e muito menos, as causas sócio-econômicas determinantes do seu desempenho" (KRAMER, 1995, p. 98). A autora cita o Parecer 2.521, de 1975, do Conselho de Educação, que justifica a opção por programas de cunho compensatório:

Enquanto não se eliminar a principal causa da reprovação maciça que se observa nas primeiras séries do ensino brasileiro de $1^{\circ}$ grau, causa essa que reside na falta de prontidão para a aprendizagem de que sofrem as crianças advindas das camadas menos privilegiadas da população, não se terá cumprido inteiramente no Brasil o mandamento constitucional da igualdade de oportunidades educacionais (BRASIL, 1975, apud KRAMER, 1995, p. 98).

A defesa do poder público, em relação à educação compensatória, também é exposta no Parecer 1.038 de 1977, quando reconhece que:

Ninguém mais coloca em dúvida o fato de que a pré-escola, se viesse a formular e executar programas de compensação das carências culturais trazidas pelas crianças oriundas de meios sociais menos privilegiados que se situam na periferia urbana e nas zonas rurais, poderia oferecer uma eficaz terapêutica para as mais gritantes deficiências de aprendizagem que essa população apresentar ao iniciar, aos sete anos de idade, o seu processo formal de escolarização (BRASIL, 1975, apud KRAMER, 1995, p. 99).

Na percepção de Kramer (1995, p. 103), propor a educação compensatória para "transformar um quadro que é determinado pelo contexto sócio-econômico, representa escamotear as verdadeiras causas que determinam o fracasso", pois não se discute a organização da sociedade em termos de infraestrutura social, econômica e distribuição de rendas, mas, ao contrário, se "distorce o conceito 
básico da contradição inerente à sociedade de classes, em que a situação marginal e a não participação são elementos fundamentais para a manutenção do sistema capitalista" (KRAMER (1995, p. 104). Na realidade, o que esses programas compensatórios pretendiam era buscar soluções para os problemas sociais mais amplos, a partir da organização das escolas e da aprendizagem dos alunos das classes menos favorecidas.

É nesse sentido que se fundamenta o sentimento de "déjà vu" mencionado por Pinazza e Santos (2016, p. 35), pois “a obrigatoriedade da pré-escola, prevista pela EC59/09, ao ter como foco as menores idades, traz uma ameaça real à Educação Infantil em suas especificidades”. Além disso:

Há em documentos do passado mais remoto e também nos atuais duas naturezas de discursos distintas: uma, que fala de uma pré-escola respeitada em suas especificidades e, outra, que apela a uma pré-escola comprometida com a etapa escolar subsequente. No entanto, não se esclarece que tipo de comprometimento é esse, o que permite a convivência de interpretações plurais (PINAZZA; SANTOS, 2016, p. 40).

A defesa do poder público em favor da obrigatoriedade, igualmente ao que ocorreu nos anos setenta, "ancora-se no argumento de que ela pode impactar positivamente o aproveitamento no ensino fundamental e no ensino médio" (FARENZENA, 2010, p. 204). Ao defender a universalização da pré-escola e demais etapas, o então ministro da Educação Fernando Haddad, em audiência pública, explicou que $30 \%$ das crianças de quatro a cinco anos e $18 \%$ dos jovens de 15 a 17 anos estão fora da escola, e relacionou a falta de acesso à pré-escola ao fracasso escolar nas séries posteriores da escolaridade, sobretudo, na população de baixa renda (FARENZENA, 2010).

Embora os argumentos de universalização de acesso e de garantia de maior tempo de permanência na escola sejam louváveis, o problema reside na responsabilização da pré-escola como espaço de preparação para os anos iniciais do ensino fundamental. Isso nos leva a crer que a justificativa do referido ministro assemelha-se, em muito, à da propagada utilizada na década de setenta e anos subsequentes, principalmente, pelo discurso em favor da pré-escola como etapa preparatória para os anos iniciais do ensino fundamental, o que nos permite uma percepção de volta ao passado e de um retrocesso em relação à educação da criança em espaços coletivos.

Nascimento (2011) explica que, do ponto de vista da prática dos professores, a excessiva escolarização da criança, evidenciada pela organização do tempo, do espaço e da proposta pedagógica, que não condiz com a faixa etária de quatro a cinco anos, desrespeita as peculiaridades da criança e fragmenta a educação infantil, já que a creche foi excluída do processo de universalização desse nível de ensino. 
Farenzena (2010) argumenta que, como a educação um direito público e subjetivo, de acordo com a legislação, esse direito deveria ser garantido, por meio de políticas públicas, também nos segmentos não obrigatórios, pois:

A obrigatoriedade escolar como norma jurídica, ao longo da história do País, tem correspondência com a obrigação/dever do Estado para com a escolaridade, além de sua face de obrigação de matrícula e frequência à escola. Contudo, para além da educação considerada obrigatória, a delimitação de um nível da educação como básica tem consequências no direito à educação mais alargado, e de um dever do Estado, incluindo a oferta de vagas e de condições de qualidade que permitam o acesso, a permanência e a conclusão das etapas da escolaridade básica (p. 205).

Conforme Campos e Barbosa (2016), a educação infantil, do ponto de vista de sua historicidade, foi concebida a partir da assistência e do favor às crianças pobres e suas famílias, e não como um direito. Por isso, o dever do Estado no provimento e na garantia desse direito torna-se urgente, pois, embora seja possível constatar um "avanço no reconhecimento legal dos direitos das crianças, compreendendo a educação numa perspectiva de direito universal subjetivo, no contexto da prática, esses direitos ainda não foram efetivados" (CAMPOS; BARBOSA, 2016, p. 70), principalmente, no que diz respeito ao ingresso das crianças menores de três anos de idade em creches.

Segundo informações estatísticas da Educação Básica (BRASIL/NEP, 2013), enquanto 2.730.119 crianças foram matriculas em creches, 4.860481 foram inseridas na pré-escola, o que demonstra a existência de um desequilíbrio no atendimento à "infầncia no país, evidenciando como a focalização no atendimento formal das crianças em idade mais próxima da escolarização sempre foi prioridade" (CAMPOS; BARBOSA, 2016, p. 71).

Dados de outra pesquisa de Campos (2013), realizada anteriormente, comprovam que, nas regiões mais desenvolvidas, as taxas de matrícula em creche são mais elevadas do que nas demais, assim como nas áreas urbanas, quando comparadas às áreas rurais. A situação econômica das famílias também compromete o ingresso das crianças em creches, pois o estudo constatou que as que apresentam "renda per capita mais baixa, também apresentam taxas de matrícula significativamente mais baixas, assim como as crianças não brancas" (CAMPOS, 2013, p. 31). Outro dado importante diz respeito ao atendimento de "crianças muito pequenas em creches, por longas horas diárias, sem a garantia de condições mínimas de qualidade, o que pode prejudicá-las em seu desenvolvimento e desrespeitá-las em seus direitos" (p. 36). 
Nessa perspectiva, Rosemberg (2010, p. 181) esclarece que, do ponto de vista histórico, a educação infantil, da maneira como foi concebida, "não escapa à lógica de produção e reprodução da pobreza via políticas públicas: as crianças pobres tendem a frequentar instituições de pior qualidade", enquanto as crianças das classes sociais mais abastadas têm acesso às melhores escolas. $\mathrm{Na}$ prática, "o acesso das crianças até três anos de idade às creches é marcado pela insuficiência e desigualdade na cobertura e por baixos padrões de qualidade” (ROSEMBERG, 2010, p. 184).

Essa situação decorre da ampliação da obrigatoriedade na América Latina como um todo, de acordo com Campos (2010b), fruto de "um contexto marcado pelo acirramento das contradições sociais, que engendram políticas sociais restritas e focais, típicas dos países de capitalismo dependente" (CAMPOS, 2010b, p. 300). É nesse contexto que se situa a dificuldade na consolidação da ampliação do acesso também para as crianças menores de três anos de idade, pois:

No caso específico da educação infantil, na maioria dos países da região, sua expansão vem sendo induzida pela combinação de dois mecanismos: adoção de pelo menos um ano de obrigatoriedade na pré-escola, associada à ampliação de atendimento "socioeducativo", em especial para as crianças de zero a três anos, via "educação não formal". Ou seja, os governantes têm optado pela focalização do atendimento nas instituições públicas para crianças de quatro-cinco anos, na perspectiva da universalização do direito à educação (p. 300).

Campos (2010b) explica que o Brasil e outros países da America Latina procuraram modernizar seus respectivos sistemas educacionais nas últimas décadas, porém, "não extinguiram estruturas que mantêm a educação ainda como um privilégio de poucos. Isto decorre da conservação de mecanismos excludentes, no interior dos sistemas educativos" (CAMPOS, 2010b, p. 300). Nesse sentido, a autora reconhece que a obrigatoriedade estabelecida pela Emenda Constitucional $\mathrm{n}^{\mathrm{o}}$ 59, de 2009, trouxe muitos desafios, entre os quais, talvez, o mais importante seja a universalização da educação infantil como um todo, a começar pela creche.

Assim, torna-se urgente e necessário pensar a creche, que desde seu surgimento constituiu um espaço de assistência a crianças pobres, com profissionais pouco qualificados, como uma instituição acessível em termos de acesso e de trabalho pedagógico que respeite os direitos fundamentais de todas as crianças até três anos de idade. Entretanto, "identificar bebês e crianças pequenas como grupo distinto dos adolescentes, dos jovens ou dos adultos decorre de uma configuração política, econômica e cultural", o que, segundo Machado (2000, p. 193), demanda uma compreensão profunda das peculiaridades dessas crianças pela sociedade como um todo. 
Como a legislação estabelece que a criança é sujeito de direitos desde o nascimento, é possível afirmar que, independente de sua classe social de origem, ao ser concebida, "passa a ser alguém que possui mais que um lugar na vida da mãe, do pai ou da família, tornando-se um sujeito de direitos: direito à vida, à saúde, à alimentação, à cultura, à dignidade, ao respeito" (MACHADO, 2000, p. 194) e, sobretudo, à educação de qualidade. A formação de profissionais, nesse sentido, também se torna um grande desafio, pois, diante da determinação legal da oferta de vagas, haverá, também, a necessidade de mais profissionais qualificados.

Machado (2000, p. 196) salienta que os projetos de formação de professores para educação infantil deverão se basear em uma "pedagogia calcada nas interações entre crianças e adultos", por meio da mediação desse último, que é mais experiente e deve possibilitar a construção de significados e a ampliação do universo infantil. Para essa autora, os processos formativos desses profissionais devem contemplar o rompimento com práticas tradicionais de organização pedagógica que desrespeitam as especificidades das crianças. Nesse sentido, a perspectiva de um trabalho inovador ampara-se na necessidade de "garantir o respeito às necessidades e interesses da criança, os padrões e valores da cultura e da sociedade em que ela se encontra", assim como, de ampliar, cotidianamente, as fronteiras de seu universo (p. 196).

Uma formação altamente qualificada se concretiza por meio de projetos que possibilitem "uma compreensão teórica e metodológica que abarque os cuidados e a educação, de maneira integrada, da criança de zero a cinco anos de idade" (PASCHOAL; BRANDÃO, 2015, p. 8). Nesse sentido, a Política Nacional de Educação Infantil (2006) define como principais objetivos para essa etapa educacional: a expansão da oferta de vagas; o fortalecimento das instâncias competentes; e, sobretudo, a garantia de uma "concepção de educação e cuidado como aspectos indissociáveis das ações dirigidas às crianças e a promoção da melhoria da qualidade do atendimento" (BRASIL, 2006, p. 10).

Daí a importância da elaboração de projetos de formação de professores que tenham como ponto de partida e de chegada a construção de um trabalho coletivo que possibilite o "atendimento integral à criança, considerando seus aspectos físico, afetivo, cognitivo, sociocultural, bem como as dimensões lúdica, artística e imaginária” (BRASIL, 2006, p. 20).

Nesse contexto, a formação inicial e continuada desses profissionais deve garantir articulação e trabalho coletivo entre os cursos de formação e as escolas infantis, por meio da elaboração e implementação de propostas pedagógicas que possibilitem à criança "apropriação, renovação e articulação de conhecimentos e aprendizagens de diferentes linguagens, assim como o 
direito à brincadeira e a interação com outras crianças" (BRASIL, 2010, p. 18). Para tanto, é fundamental a valorização dos professores e a participação dos mesmos em programas de formação inicial e em exercício, assim como, sua inclusão nos planos de cargos e salários do magistério.

Saviani (2009) entende que a formação e a atuação de professores devem estar atreladas às condições de trabalho, principalmente, em relação às questões de salário e jornada de trabalho. Uma boa formação não garante uma prática eficaz, pois as "condições precárias de trabalho, não apenas neutralizam a ação dos professores, mesmo que estes sejam bem formados" (SAVIANI, 2009, p. 153). Para o autor, não é possível garantir uma formação consistente sem recursos financeiros suficientes, pois:

É preciso acabar com a duplicidade pela qual, ao mesmo tempo em que se proclamam aos quatro ventos as virtudes da educação exaltando sua importância decisiva num tipo de sociedade como esta em que vivemos, classificada como "sociedade do conhecimento", as políticas predominantes se pautam pela busca da redução de custos, cortando investimentos. Faz-se necessário ajustar as decisões políticas ao discurso imperante (p. 153).

Nessa perspectiva, Freitas (2007, p. 1204) defende uma política de formação e valorização de professores "que contemple de forma articulada e prioritária a formação inicial, formação continuada e condições de trabalho, salários e carreira, com a concepção sócio-histórica do educador a orientá-la”. Entretanto, aponta a dificuldade de sua materialização em uma organização social desigual e excludente como a nossa, que "nos permite entender e atuar no campo das contradições e evita que possamos cair na armadilha das soluções fáceis, ágeis e de menor custo, que caracterizam, via de regra, as iniciativas no âmbito da educação e da formação" (FREITAS, 2007, p. 1220).

A defesa de Freitas (2007) é pela expansão da escolarização e do papel do Estado na disponibilização de recursos financeiros que garantam a expansão da educação superior pública, presencial e de qualidade, sobretudo no que tange aos processos formativos de professores. A fim de contribuir para o estabelecimento de uma política global de formação mais emancipadora e menos fragmentada, a autora elenca três importantes perspectivas de trabalho:

1) Uma ação conjunta entre as universidades e demais instâncias formadoras e os sistemas de ensino, de maneira a rever a formação básica, assegurar condições dignas de trabalho e formação continuada; 2) a revisão das estruturas das instituições formadoras do profissional da educação, experienciando novas maneiras de organizar a formação do educador e avançando para formas de organização por cursos e programas, para todos os níveis de ensino, contemplando a formação inicial e 
continuada; 3) o estabelecimento de uma integração permanente entre as instituições de formação do profissional da educação, as entidades organizadas dos trabalhadores da educação e demais entidades da área educacional, na instituição e fortale cimento de fóruns coletivos de debate e indicação de políticas de formação e valorização profissional (FREITAS, 2007, p. 1220).

Acreditamos, assim como Saviani (2009) e Freitas (2007), que uma educação de qualidade não se consolida somente com bons projetos de formação de professores, mas, sobretudo, por meio da valorização social e financeira de seus profissionais. Desse modo, é possível transformar a “docência numa profissão atraente socialmente em razão da sensível melhoria salarial e das boas condições de trabalho" (SAVIANI, 2009, p. 154), visto que a educação é um direito de todos e dever do Estado.

Se, por outro lado, reconhecemos os avanços da legislação, que assegura o direito da criança à educação desde o nascimento, inversamente, constatamos significativos retrocessos na trajetória legal da educação infantil, em função da precarização dos serviços prestados. Portanto, a nossa defesa é pela universalização dessa instituição, que deve abarcar creche e pré-escola como espaços eminentemente pedagógicos, que cuidam, educam e acolhem nossas crianças, com base em uma formação mais abrangente de nossos professores.

\section{CONSIDERAÇÕES FINAIS}

À luz dos elementos analisados, podemos afirmar que os avanços da legislação, nas últimas décadas, não foram suficientes para consolidar a educação infantil como direito de todas as crianças brasileiras, visto que a enorme disparidade de acesso entre a creche e a pré-escola ainda constitui um grande desafio para as políticas públicas destinadas às crianças com até cinco anos de idade. Por outro lado, o reconhecimento do direito à educação desde o nascimento, contemplado na Constituição Federal (1988), possibilitou sua inserção como primeira etapa da Educação Básica na organização dos sistemas de ensino no Brasil.

Uma nova configuração desses espaços em termos de currículo, formação de professores e serviços prestados se tornaram realidade em termos legais, mas que precisam se concretizar no cotidiano das escolas infantis. Nesse sentido, mais do que um lugar na familia e na comunidade, a criança têm direito à educação de qualidade, por meio de um trabalho pedagógico que cumpra a finalidade da educação infantil de promover o desenvovimento integral da criança até cinco anos de idade. A obrigatoriedade da entrada da criança a partir dos quatro anos, não pode, portanto, representar a fragmentação dos serviços prestados e a ruptura entre a creche e a pré-escola. 
A implementação de projetos de formação se torna urgente e necessária, visto que o grande desafio é garantia de políticas públicas de formação inicial e continuada que possibilitem aos professores a construção de práticas que reconheçam as especificidades desse nível de ensino. Além disso, faz-se necessário políticas formativas atreladas à valorização social e financeira, bem como a superação da precariedade na preparação didático-pedagógica docente. Desse modo, reconhecemos que muitos desafios se impõem frente às determinações legais, sobretudo no que tange à formação e universalização da educação infantil no Brasil.

\section{REFERÊNCIAS}

BRASIL. Constituição da República Federativa do Brasil. Diário Oficial da União. Brasília, DF: Senado Federal, 1988. 305 p.

\section{0.}

Estatuto da Criança e do Adolescente. Lei 8.069, de 13 de junho de 1990. Diário Oficial da União. Brasília:

Lei de Diretrizes e Bases da Educação Nacional. Lei 9.394, de 20 de dezembro de 1996. Dispõe sobre as Diretrizes e Bases da Educação Nacional. Diário Oficial da União. Brasília, DF: MEC, 1996.

. Ministério da Educação e do Desporto. Secretaria de Educação Básica. Política nacional de educação infantil. Diário Oficial da União. Brasília, DF: MEC/SEB, 2006.

Emenda Constitucional 59, de 11 de novembro de 2009. Acrescenta § 3o ao artigo 76 do ato das disposições constitucionais transitórias. Diário Oficial da União. Brasília: 12 nov. 2009. Seção 1, p.8.

Parecer CNE/CEB 020/2009; Resolução CNE/CEB N. 5/2009. Diretrizes Curriculares Nacionais para a Educação Infantil. Diário Oficial da União. Brasília, DF: Conselho Nacional de Educação/Câmara da Educação Básica, 2010.

Lei 12.796 de 04 de abril de 2013. Altera a Lei 9.394 de 20 de dezembro de 1996-LDB. Diário Oficial da União. Brasília: 2013.

CAMPOS, Maria Malta. Educar e cuidar: questões sobre o perfil do profissional de educação infantil. In: BRASIL. Por uma política de formação do profissional de educação infantil. Brasília: MEC, 1994. p. 32-42.

A Educação infantil como direito. In: Insumos para o debate 2: Emenda Cconstitucional 59 de 2009 e a educação infantil: impactos e perspectivas. São Paulo: Campanha Nacional pelo direito à educação, 2010a. p. 8-14.

Entre as políticas de qualidade e a qualidade das práticas. Cadernos de Pesquisa, n. 148, p. $22-43,2013$. Disponível em: 〈www.scielo.br/pdf/cp/v43n148/03.pdf>. Acesso em: 20 dez. 2017.

CAMPOS, Roselane F. Democratização da educação infantil: as concepções e políticas em debate. Revista Retratos da Escola, Brasília, v. 4, n. 7, p. 299-311, jul./dez. 2010b. Disponível em: 〈http//www.esforce.org.br>. Acesso em: 05 jan. 2018.

CAMPOS, Rosânia; BARBOSA Maria C. Silveira. Obrigatoriedade de matrícula aos quatro anos: ampliação ou recuo do direito?. Textura Canoas, v. 18, n. 36 p. 66-86. jan./abr. 2016. Disponível em: <www.periodicos.ulbra.br/ index.php/txra/article/download>. Acesso em: 10 nov. 2017.

DIDONET, Vital. Nota de esclarecimento sobre a PEC 277/2008. [S.1.: s.n.], 2009. (Digitado).

FARENZENA, Nalú. A Emenda da obrigatoriedade: mudanças e permanências. Revista Retratos da Escola, Brasília, v. 4, n. 7, p. 197-209, jul./dez. 2010. Disponível em: 〈http//www.esforce.org.br>. Acesso em: 10 jan. 2018.

FREITAS, Helena C. A. (Nova) política de formação de professores: a prioridade postergada. Educação e Sociedade. Campinas, vol. 28, n. 100 - Especial, p. 1203-1230, out. 2007. Disponível em: 〈http://www.cedes.unicamp.br〉. Acesso em: 10 jan. 2018.

KRAMER, Sonia. A política do pré-escolar no Brasil: a arte do disfarce. 5. ed. São Paulo: Cortez,1995. 
MACHADO, Maria Lúcia de A. Desafios iminentes para projetos de formação de profissionais para educação infantil. Cadernos de Pesquisa, n. 110, jul. 2000. Disponível em: 〈http://www.scielo.br/scielo〉. Acesso em: 10 jan. 2018.

NASCIMENTO. Maria L. Algumas considerações sobre a infância e as políticas de educação infantil. Educação \& Linguagem, v. 14, n. 23/24, p. 146-159, jan./dez. 2011. Disponível em: <https://www.metodista.br/revistas/revistas ims/index.php>. Acesso em: 22 out. 2017.

PASCHOAL. Jaqueline D. BRANDÃO, Carlos da F. A Contribuição da legislação para a organização do trabalho pedagógico na educação infantil brasileira. Revista HISTEDBR On-line, Campinas, n. 66, p. 196-210, dez. 2015. Disponível em: <https://periodicos sbu.unicamp.br>. Acesso em: 20 out. 2017.

PINAZZA, Mônica Ap.; SANTOS, Maria W. A (Pré)-escola na lógica da obrigatoriedade: um desconcertante 'dejà vu'?. Textura Canoas, v. 18, n. 36, p. 22-43 jan./abr. 2016. Disponível em: <www.periodicos.ulbra.br/index.php/txra/ is sue/view/147>. Acesso em: 20 jan. 2018.

ROSEMBERG, F. Educação Infantil pós-Fundeb: avanços e tensões. In: SOUZA, G. (Org.). Educar na Infância: pers pectivas histórico-sociais. São Paulo: Contexto, 2010. p. 171-186.

SAVIANI, D. Formação de professores: aspectos históricos e teóricos do problema no contexto brasileiro. Revista Brasileira de Educação, Rio de Janeiro, v. 14, n. 40, p. 143-155, jan./abr. 2009. Disponível em: 〈www.scielo.br/pdf>. Acesso em: 04 ago. 2017.

SILVA, Andréia Ferreira da. Escolarização obrigatória e formação de professores para a educação infantil. Revista Retratos da Escola, Brasília, v. 5, n. 9, p. 371-383, jul./dez. 2011. Disponível em: 〈http//www.esforce.org.br〉. Acesso em: 10 jan. 2018. 


\section{RESUMO}

O artigo tem por objetivo discutir a formação de professores a partir da obrigatoriedade da pré-escola, prescrita pela Emenda Constitucional no 59, de 2009. A falta de compreensão sobre as especificidades dessa etapa da Educação Básica, aliada à formação precária de seus profissionais, pode levar a um retrocesso histórico por meio de práticas de antecipação da escola, como ocorreu nos meados da década de setenta, devido à formalização da educação pré-escolar no Brasil. Diante disso, consideramos que inúmeros são os desafios e as perspectivas no que diz respeito à formação, pois todas as crianças têm direito à educação de qualidade desde o nascimento, para além da obrigatoriedade na pré-escola.

Palavras-chave: Educação Infantil. Obrigatoriedade. Processos Formativos.

\section{THE MANDATORY PRE-SCHOOL IN BRAZIL AND CHALLENGES IN TEACHER TRAINING}

\section{ABSTRACT}

The purpose of this article is to discuss the training of teachers based on the compulsory pre-school, prescribed by Constitutional Amendment No. 59, 2009. The lack of understanding about the specifics of this stage of Basic Education, coupled with the precarious formation of its professionals, can lead to a historical regression through practices of anticipation of the school, as occurred in the mid-seventies, due to the formalization of pre-school education in Brazil. Questions about the organization of time and space and the use of activities similar to those of elementary education, especially early literacy, are dilemmas faced in the daily life of children's schools. Given this, we consider that there are many challenges and perspectives regarding training, since all children have the right to quality education from birth, in addition to compulsory preschool.

Keywords: Infant Education. Obligatoriness. Formative Processes.

\section{LA PRÉ-ESCUELA OBLIGATORIA EN BRASIL Y LOS DESAFÍOS EN LA FORMACIÓN DE PROFESORES}

\section{RESUMEN}

El artículo tiene por objetivo discutir la formación de profesores a partir de la obligatoriedad de la preescolar, prescrita por la Enmienda Constitucional n 59, de 2009. La falta de comprensión sobre las especificidades de esa etapa de la Educación Básica, aliada a la formación precaria de sus profesionales, puede llevar a un retroceso histórico por medio de prácticas de anticipación de la escuela, como ocurrió a mediados de la década de 1970, debido a la formalización de la educación preescolar en Brasil. Las cuestiones sobre la organización del tiempo y del espacio y el uso de actividades similares a las de la enseñanza fundamental, sobre todo, la alfabetización precoz, son dilemas enfrentados en el cotidiano de las escuelas infantiles. Por eso, consideramos que muchos son los desafíos y las perspectivas en lo que se refiere a la formación, pues todos los niños tienen derecho a la educación de calidad desde el nacimiento, además de la obligatoriedad en la preescolar.

Palabras clave: Educación infantil. Obligación, Procesos Formativos.

Submetido em: 06 de julho de 2018 Aprovado em: 30 de abril de 2019 